\title{
A Comparative Study on Vocabulary Learning Strategies by Chinese English Majors and Non-English Majors
}

\author{
Tian Tian \\ College English Teaching \& Research Office, School of Foreign Languages \& Cultures, Beijing Wuzi University, Beijing, China \\ Email address: \\ tiantian@bwu.edu.cn \\ To cite this article: \\ Tian Tian. A Comparative Study on Vocabulary Learning Strategies by Chinese English Majors and Non-English Majors. International \\ Journal of Applied Linguistics and Translation. Vol. 5, No. 4, 2019, pp. 89-94. doi: 10.11648/j.ijalt.20190504.17
}

Received: November 17, 2019; Accepted: November 25, 2019; Published: December 2, 2019

\begin{abstract}
The present study aims to explore English vocabulary learning beliefs and strategies employed by English majors and non-English majors. A questionnaire was administered to 210 students (105 English majors and 105 non-English majors) from two universities to explore English vocabulary learning beliefs and strategies employed by English majors and non-English majors in China. The questionnaire is adapted from $\mathrm{Gu}$ and $\mathrm{Hu}$ [1]. Statistical descriptions and independent samples t-test are undertaken to process the data collected. The analyses of the data reveal both Chinese English and non-English majors are interested in learning vocabulary. They report adopting a number of learning strategies in their vocabulary learning processes. They appear to use metacognitive strategies more often when they learn vocabulary, especially self-initiation. At cognitive level, they are both inclined to adopt dictionary use, guessing, note-taking and activation strategies very often, while encoding and rehearsal are less used. English majors' strategy use frequencies seem all higher than non-English majors, except note-taking strategies. English majors show significant differences from non-English majors in some vocabulary learning strategies like: self-initiation, dictionary use and contextual guessing. The study suggests that teachers should encourage students to hold a positive belief on vocabulary learning and to employ both metacognitive and cognitive strategies in learning vocabulary. Students should pay as much attention to cognitive strategies as to metacognitive strategies.
\end{abstract}

Keywords: English Majors, Non-English Majors, Vocabulary Learning Beliefs, Vocabulary Learning Strategies

\section{Introduction}

Vocabulary plays an important role in second language teaching and learning. Vocabulary knowledge is known to be crucial for reading comprehension and for dealing with academic content in a second language [2-3]. One cannot learn a language without vocabulary [4-5]. Vocabulary plays an important role in second language learning.

Learning strategies play significant roles in acquisition of a language. In the last three decades or so, considerable research has been done on language learning strategy and various learner variables affecting the choice and use of learning strategies in the world of second language acquisition [6-9]. Nowadays, some linguists and educators [10-12] have already begun their studies on vocabulary learning strategies.

From the research to date, the studies on vocabulary learning strategies have provided us with some of the richest insights into the kinds of behaviors associated with successful language learning. It is evident that all language learners use learning strategies of some kind; however, the frequency and variety of strategy use vary between different learners and under different conditions. Current studies tend to focus on individual or small numbers of strategies [13]; there are "very few studies looking at the group as a whole" [14].

The purpose of the present survey is to describe beliefs and vocabulary learning strategy patterns the students in Chinese universities exhibit. The comparative study can help teachers better facilitate students with their vocabulary acquisition. The most important is to cultivate the students' strategy awareness and let them make appropriate and flexible use of each vocabulary strategy category.

\section{Literature Review}

\subsection{Language Learning Strategies and Vocabulary Learning Strategies}

Researchers have been aiming at eliciting the useful 
strategies applied by successful language learners, assuming that this could help other learners to become more successful How to classify language learning strategies still remain open to debate [15]. O'Malley and Chamot's classified the language learning strategies into three major types: cognitive strategies, meta-cognitive strategies and social/affective strategies [8]. The three types of strategies are meta-cognitive strategies, cognitive strategies and social/affective strategies. According to Rod Ellis, the significant feature of Oxford's framework is the distinction made between direct and indirect strategies [16]. Examining the two classifications above, Oxford's direct strategies are like O'Malley and Chamot's cognitive strategies, and her indirect strategies are like O'Malley and Chamot's metacognitive strategies and social/affective strategies. The main difference lies in that Oxford puts the direct and indirect strategies at the same level, supporting each other, while O'Malley and Chamot assert metacognitive strategies are at higher order than other two strategies.

Schmitt developed an extensive taxonomy of vocabulary learning strategies, which was organized on the basis of Oxford's social, memory, cognitive, and metacognitive strategies [14]. In order to cover cases where meanings of new words are discovered without other people's assistance, Schmitt introduced determination strategies. Schmitt's taxonomy is two-dimensional, discovery strategies and consolidation strategies. Moreover consolidation strategies was borrowed from Nation [5].

\subsection{Related Studies on Strategy Use in Learning Vocabulary}

Many researchers take great interest in the strategy use on vocabulary learning by language learners [17-18, 10]. In studies taking vocabulary learning strategies as a whole, Ahmed studied 300 Sudanese learners of English and identified members in "good learner" groups used vocabulary learning strategies more and flexibly [19]. Fan's study conducted in Hong Kong, which aims to investigate the frequency of use, perceived usefulness, and actual usefulness of second language vocabulary learning strategies of 1067 learners [13].

Schmitt asked a total of 600 Japanese students and company employees with regard to actual strategy use and perceived helpfulness [14]. The "winner" in both categories proved to be consulting a bilingual dictionary; other popular strategies took the order as written and verbal repetition, study spelling of a word, and guessing from context. Nation focuses attention on three vocabulary learning strategies: guessing the meanings of words in context, using mnemonic techniques to remember word meanings and using prefixes, roots, and suffixes to learn or guess unfamiliar words [5]. Liu Jinkai studied the vocabulary learning strategy "guessing meaning". He argued "guessing meaning" played an important role in students' acquisition of vocabulary [11-12]. However, this strategy has limitation to some extent [20]. Ahmed discovered that note-taking is a strategy Sudanese L2 learners used very frequently [19]. Leeke and Shaw investigated 121 overseas postgraduate and 81 reported to note down or recently note down new vocabulary [21]. The intermediate-level ESL students of mixed ethnic backgrounds were examined and found that Asian students prefer to rely on rote repetition [22]. Ellis and Beaton investigated students learning German and using repetition and keyword strategy [23]. Some scholars found that extensive reading is an effective vocabulary learning strategy $[4,20]$. Levin compared the keyword method with context method and finds that subjects in the keyword condition performed better than subjects in the contextual condition [cited in 20].

\section{Methodology}

\subsection{Participants}

210 college students from Dalian Maritime University and Tianjin Foreign Studies University participated in the survey. The age range of these participants was 19-21. They have studied English for 10-12 years since Chinese students begin learning English in primary school. They were from two departments: Marine Engine Engineering (from Dalian Maritime University) and Educational Technology (from Tianjin Foreign Studies University).

\subsection{Instruments}

A vocabulary learning questionnaire-VLQ Version 5 by Gu and $\mathrm{Hu}$ was adopted to elicit students' beliefs about vocabulary learning and their self-reported vocabulary learning strategies [1]. The questionnaire, written in Chinese, reflected previous quantitative and qualitative research [18]. It has two sections including three dimensions, which are beliefs about vocabulary learning, metacognitive strategies and cognitive strategies. Participants had to rate each statement on a 7-point scale from Absolutely Disagree (1) to Absolutely Agree (7). 4 is seen as the medium level of a strategy use. If the mean value is more than 4 , it can be inferred that the strategy is often used or always used by the subjects whereas a mean value smaller than 4 indicates that the strategy is less used.

\subsection{Procedures}

The survey was undertaken in Dalian Maritime University in September, 2018 and in Tianjin Foreign Studies University in October, 2018. The survey was administered during class time. Before students answered the questionnaire, written instructions were repeated orally to the participants by teachers in charge of the class.

93 English majors and 91 non-English majors provided valid questionnaires. Descriptive statistics such as means, standard deviations were gained first to see the overall patterns of vocabulary learning strategies adopted by both English majors and non-English majors. Then independent samples t-test was employed to examine whether there are significant differences in their use of three dimensions of vocabulary learning strategies between English majors and non-English majors and how they varied. 


\section{Results and Discussions}

\subsection{The Current Situations of Vocabulary Learning Strategies Adopted by English and Non-English Majors}

\subsubsection{Beliefs and Vocabulary Learning Strategies of English Majors}

The internal reliability the questionnaire is .907 . The overall learning strategy $(\mathrm{M}=4.41, \mathrm{SD}=.45)$ shows English majors are inclined to use vocabulary learning strategies in their vocabulary learning. This finding is similar to those reported in Wu and Wang's and Gu and Hu's study [10, 1].

English majors prefer belief "words should be learned through use" $(\mathrm{M}=5.30)$ to "words should be memorized" $(\mathrm{M}=3.27)$. According to $\mathrm{Gu}$ and $\mathrm{Hu}$, if the mean value of a strategy is larger than 4.5 , the strategy can be regarded as a high-level strategy [1]. Krashen advocated that words should be acquired naturally through reading extensively, which corresponds to the belief of English majors [4].

Selective attention and self-initiation, the two categories of metacognitve strategies are all often used by English majors. Self-initiation is a popular strategy among English majors $(\mathrm{M}=4.94, \mathrm{SD}=.86)$ and selective attention $(\mathrm{M}=4.32, \mathrm{SD}=.93)$ is a comparative popular strategy. These two strategies are above the medium level. Learners who employ selective attention strategies know which words are important for them to learn and are essential for adequate comprehension of a passage, and learners employing self-initiation strategies use a variety of means to make the meaning of vocabulary items clear [24].

The ranking order of cognitive strategies is as follows: dictionary use $(\mathrm{M}=5.05, \mathrm{SD}=.71)$, guessing $(\mathrm{M}=4.76$, $\mathrm{SD}=.70)$, note-taking $(\mathrm{M}=4.40, \mathrm{SD}=.87)$, activation $(\mathrm{M}=4.36$, $\mathrm{SD}=.92)$, encoding $(\mathrm{M}=4.02, \mathrm{SD}=.65)$ and rehearsal $(\mathrm{M}=3.93$, $\mathrm{SD}=.76$ ). Both dictionary use and guessing belong to the high level. Just like Nation pointed out, "it is important that it includes a large number of words and idioms, gives information about the meaning and appropriateness of words" [5]. Nation also championed guessing from context as the "undoubtedly most important vocabulary learning strategy" [5]. Rehearsal strategies are the least used in the survey. According to $\mathrm{Wu}$ and Wang, although the students have already been aware that words should be learned through use, they are still adopting various memorization strategies they are familiar with, thus it is important to help English learners to form and use some vocabulary learning strategies [10].

\subsubsection{Beliefs and Vocabulary Learning Strategies of Non-English Majors}

The questionnaire of non-English majors shows an internal consistency coefficient of .923. The overall pattern of vocabulary learning strategies use $(\mathrm{M}=4.27, \mathrm{SD}=.54)$ indicates non-English majors often use vocabulary learning strategies when they meet new words.

Beliefs of non-English majors on vocabulary learning place a mean of 4.29 and SD of .53. Non-English majors are also interested in learning vocabulary. "Words should be learned through use" $(\mathrm{M}=5.20, \mathrm{SD}=.70)$ is much more popular than "words should be memorized" $(\mathrm{M}=3.37, \mathrm{SD}=.92)$ for non-English majors, similar to some previous studies $[10,1]$.

Metacognitive strategies $(\mathrm{M}=4.36, \mathrm{SD}=.73)$ are often employed by non-English majors. Both selective attention and self-initiation are scored above 4 , with the means of 4.10 and 4.61 respectively. The two categories are both used by non-English majors frequently, especially self-initiation, which is in accordance with Gu and Johnson's study [18].

Non-English majors adopt extended dictionary strategies $(\mathrm{M}=4.69, \mathrm{SD}=1.10)$ most often, just as the result of English majors' beliefs. Non-English majors use note-taking ( $\mathrm{M}=4.50$, $\mathrm{SD}=.92$ ) as the second most frequent strategies, while English majors treat guessing strategies as the second most frequent. The strategies next to note-taking are contextual guessing strategies, which are also often used $(\mathrm{M}=4.47, \mathrm{SD}=.79)$. Activation strategies $(\mathrm{M}=4.29, \mathrm{SD}=.91)$ by non-English majors rank the fourth, but higher than medium level 4 . Ghazal explained that activation strategies include those strategies through which the learners actually use new words in different contexts [24]. Encoding strategies are also less popular for non-English majors. In the case of rehearsal strategies, non-English majors use least in the survey, as Nation mentioned, "Some psychologists believe that repetition is not an important factor in vocabulary learning." [25]

\subsection{Comparison of Beliefs and Strategy Use Between English Majors and Non-English Majors}

An independent samples t-test was administrated to see the differences between English majors and non-English majors in terms of their vocabulary learning strategies.

\subsubsection{Comparison of Overall Strategies and Three Dimensions Between English Majors and Non-English Majors}

Table 1. Comparison of Overall Strategies and Three Dimensions between English majors and non-English majors.

\begin{tabular}{lllll}
\hline & t & Sig. (2-tailed) & Mean Difference & Std. Error Difference \\
\hline Overall strategies & .257 & .073 & .132 & .073 \\
Beliefs & .951 & .956 & -.004 & .081 \\
Metacognitive strategies & .816 & .012 & .275 & .108 \\
Cognitive strategies & .209 & .104 & .135 & .083 \\
\hline
\end{tabular}

The overall strategies used by English majors and non-English majors do not show significant difference from each other $(\mathrm{p}=.073)$, but the mean of the former is a little higher than that of the latter, indicating both English and
non-English majors often use vocabulary learning strategies. English majors have more consciousness and willingness to adopt vocabulary strategies when they undertake English language learning. 
No statistically significant difference $(\mathrm{p}=.956)$ can be seen, which means the two groups of students almost hold the same beliefs towards vocabulary learning. By referring to the former results, we can decide that English majors and non-English majors view vocabulary learning as an interesting task and they obtain a sense of success from learning vocabulary.

In terms of the metacognitive level of vocabulary learning, English majors and non-English majors do show statistically significant difference $(p=.012,<0.05)$. The mean of English majors' is 4.63, significantly higher than that of non-English majors $(M=4.35)$. Generally speaking, the students are capable of adopting actions and measures to organize and regulate their vocabulary learning processes. English majors are better at controlling and evaluating their own learning.

At cognitive level, no significance is found between English and non-English majors $(p=.104)$. This means that both English and non-English majors care for using strategies to manipulate the word information in order to acquire these new word, thus promote English language learning.

\subsubsection{Comparison at Metacognitive Level Between English Majors and Non-English Majors}

At metacognitive level, English majors and non-English majors do show statistically significant difference in the category of self-initiation $(\mathrm{P}=.015)$, the biggest difference at this level.

Table 2. Comparison at metacognitive level between English majors and non-English majors.

\begin{tabular}{lllll}
\hline & t & Sig. (2-tailed) & Mean Difference & Std. Error Difference \\
\hline Selective attention & .987 & .126 & .214 & .140 \\
Self-initiation & .282 & .015 & .335 & .136 \\
\hline
\end{tabular}

Self-initiation is very popular among English majors, indicating English majors are motivated to find other ways of enlarging their vocabulary. They are inclined to use various means to make clear vocabulary items that they don't know.

No significant difference lies between English and non-English majors in the category of selective attention. The mean of selective attention indicates that the students are conscious of choosing which words to learn. Selective attention shows that the students investigated are positive about what words are important for them to learn in a particular session. As a result, their vocabulary learning initiative would be greatly enhanced and their efficiency would be increased.

\subsubsection{Comparison at Cognitive Level Between English Majors and Non-English Majors}

Table 3. Descriptive analysis for vocabulary learning strategies at cognitive level.

\begin{tabular}{lllll}
\hline \multirow{2}{*}{ Category of strategies } & \multicolumn{2}{l}{ English majors } & \multicolumn{2}{l}{ Non-English majors } \\
\cline { 2 - 5 } & Mean & SD & Mean & SD \\
\hline Contextual guessing & 4.76 & .70 & 4.47 & .79 \\
Dictionary strategies & 5.05 & .71 & 4.69 & .83 \\
Note-taking strategies & 4.40 & .87 & 4.50 & .92 \\
Rehearsal strategies & 3.92 & .76 & 3.89 & .87 \\
Encoding strategies & 4.02 & .65 & 3.95 & .88 \\
Activation strategies & 4.36 & .92 & 4.29 & .91 \\
\hline
\end{tabular}

Table 3 gives a descriptive analysis for vocabulary learning strategies at cognitive level of English and non-English majors. Independent samples t-test has been done between English and non-English majors for the six categories, as shown in Table 4

Table 4. Comparison at cognitive level between English majors and non-English majors.

\begin{tabular}{lllll}
\hline & $\mathbf{t}$ & $\begin{array}{l}\text { Sig. } \\
\text { (2-tailed) }\end{array}$ & $\begin{array}{l}\text { Mean } \\
\text { Diference }\end{array}$ & $\begin{array}{l}\text { Std. Error } \\
\text { Difference }\end{array}$ \\
\hline Contextual guessing & .289 & .009 & .291 & .110 \\
Dictionary strategies & .325 & .002 & .354 & .114 \\
Note-taking strategies & .837 & .445 & -.101 & .131 \\
Rehearsal strategies & .223 & .768 & .036 & .121 \\
\hline
\end{tabular}

\begin{tabular}{lllll}
\hline & t & $\begin{array}{l}\text { Sig. } \\
\text { (2-tailed) }\end{array}$ & $\begin{array}{l}\text { Mean } \\
\text { Diference }\end{array}$ & $\begin{array}{l}\text { Std. Error } \\
\text { Difference }\end{array}$ \\
\hline Encoding strategies & .013 & .551 & .068 & .114 \\
Activation strategies & .840 & .586 & .073 & .135 \\
\hline
\end{tabular}

Table 4 indicates that at cognitive level, English and non-English majors show significant difference in the category of contextual guessing $(\mathrm{P}=.009,<.05)$ and dictionary use $(\mathrm{P}=.002,<.05)$.

From table 3, we can see guessing strategies by English majors $(\mathrm{M}=4.76, \mathrm{SD}=.70)$ is much higher than by non-English majors $(\mathrm{M}=4.47, \mathrm{SD}=.79)$, but both of the two groups often guess new words' meaning as the mean values are all above 4 . English majors usually guess the meaning of a word they confronted with in their reading by using their knowledge about vocabulary learning. This is because the participants are second-year and third-year English majors with some knowledge of the English language, the internal structure of English vocabulary, English culture and customs, etc. Nation pointed out that guessing from context is the most important and most powerful strategy of dealing with unknown words [5]. "In order to get a more satisfactory interpretation of unfamiliar words, the reader needs to make use of the context." [5] Second-year and third-year non-English majors have also gained some general knowledge of English language and vocabulary, as well as some sentence structures and grammatical points, however, they might not receive English inputs as comprehensively as English majors. English majors are more inclined to guess new words in a certain context.

Dictionary use by English majors $(\mathrm{M}=5.05, \mathrm{SD}=.71)$ and non-English majors $(\mathrm{M}=4.69, \mathrm{SD}=.83)$ is the highest among all the six categories respectively, which is completely in line with what Kojic-Sabo and Lighthown have found in their study [26]. Both English and non-English majors resort to dictionary use most frequently for new words learning. But one thing to be noted is that, at cognitive level, English majors employ dictionary strategies as the second most frequently used, while non-English majors take noting-taking strategies as the second favorite, dictionary strategies as the third. 
English majors are much more in favor of consulting dictionaries when they meet with some new words.

With regard to note-taking, rehearsal, encoding and activation strategies, no significant differences are found among these strategies on learning vocabulary by English and non-English majors. But English majors tend to use vocabulary strategies more often than non-English majors in relation to the four categories except note-taking strategies. Non-English majors seem to use note-taking strategies more often. A list of these statistical data is also given as in table 3 .

\section{Conclusion}

In light of the above results, this survey has some practical implications for both teachers and students.

Judging from the descriptive statistics of learners' vocabulary learning beliefs and vocabulary learning strategies, teachers should try to diagnose their students' current beliefs and strategies and provide more systematic instruction on vocabulary learning for the students while teaching English vocabulary. This can be done through surveys, interviews, etc.

To the different stress on vocabulary learning strategies adopted by English majors and non-English majors, teachers should pay much more attention to encoding and rehearsal strategies because both English and non-English majors use encoding and rehearsal strategies less often. The students investigated are not good at consolidating their vocabulary learning outcomes. Teachers are advised to help the students in this area.

Based on the findings about the differences of strategy use between English majors and non-English majors, teachers are advised to highlight more strategies such as self-initiation, dictionary use, guessing on non-English majors since they show significant difference in these strategies with English majors.

In light of results found in the survey, English and non-English majors' use of metacognitive strategies ranks first and cognitive strategies second. Thus students are firstly conscious of controlling vocabulary learning as a general process.

The study presents a comprehensive picture of English vocabulary learning beliefs and strategies employed by both English majors and non-English majors in Chinese universities. However, this survey has its own limitations. More comprehensive research on a wider range of variables affecting vocabulary learning strategy use of learners should be taken into consideration, such as social/affective strategies, motivation, gender and so on should be taken into consideration. Moreover, further research can concentrate more on the reasons of adopting some certain vocabulary learning strategies between English majors and non-English majors, and the reasons for students' smaller vocabulary size.

\section{Acknowledgements}

This work was supported by supported by Beijing Wuzi University under the education project "The Correlation between Critical Thinking Dispositions and Intercultural Competence", and thank those whose assistance and support have made this thesis a reality.

\section{References}

[1] Gu, Yongqi, Hu, Guangwei. (2003). Empirical Study on English Learning Strategies. Shaan'xi Normal University Press.

[2] Garcia, G. (1991). Factors influencing the English reading test performance of Spanish-speaking Hispanic students. Reading Research Quarterly, 26: 371-392.

[3] Nation, I. S. P. (1993). Vocabulary size, growth, and use. In R. Schreuder and B. Weltens (Eds.). 1993. The bilingual lexicon. Amsterdam: John Benjamins: 115-134.

[4] Krashen, S. (1989). We Acquire Vocabulary and Spelling by Reading: Additional Evidence for the Input Hypothesis. Modern Language Journal, 73: 440-464.

[5] Nation, I. S. P. (1990). Teaching and learning vocabulary. Boston: Heinle and Heinle.

[6] Oxford, R. (1989). Use of language learning strategies: a synthesis of studies with implications for strategy training. System, 17: 235-247.

[7] Oxford, R. (1990). Language Learning Strategies: What Every Teacher Should Know. New York: Newbury House.

[8] O'Malley, J. and A. Chamot. (1990). Learning Strategies in Second Language Acquisition. Cambridge: Cambridge University Press.

[9] Oxford, R. and R. Scarcella. (1994). Second Language Vocabulary Learning Among Adults: State of the Act in Vocabulary Instruction. System, 22: 231-243.

[10] Wu, Xia, and Wang, Qiang. (1998). The Vocabulary Learning Strategies of Non-English Majors. Foreign Language Teaching and Research (1), 53-57.

[11] Liu, Jinkai. (1999). Research on Language Learning strategies-Word Guessing and Language Proficiency. Foreign Language Education (3), 31-35.

[12] Liu, Jinkai. (2001). Research on English Vocabulary Learning-Word Guessing Strategy and Cultivation of Competence. Journal of Xi' an Foreign Languages University (4), 21-24.

[13] Fan. (2003). Frequency of use, perceived usefulness, and actual usefulness of second language vocabulary strategies: A study of Hong Kong learners. The Modern Language Journal, 87 (2): 222-241.

[14] Schmitt, N. (1997). Vocabulary learning strategies. In N. Schmitt and M. McCarthy (eds.) Vocabulary: Description, Acquisition, and Strategies. Cambridge: Cambridge University Press.

[15] Hsiao, T. and Oxford, R. (2002). Comparing theories of language learning strategies: A confirmatory factor analysis. Modern Language Journal, 86 (3): 368-383.

[16] Ellis, R. (1994). The Study of Second Language Acquisition. Oxford: Oxford University Press. 
[17] Carter, R. and M. McCarthy. (1988). Vocabulary and Language Teaching. New York: Longman Press.

[18] Gu, Yongqi and R. K. Johnson. (1996). Vocabulary learning strategies and language learning outcomes. Language Learning, 46: 643-679.

[19] Ahmed, M. O. (1989). Vocabulary learning techniques. In P Meara (Ed.), Beyond Words. London: CIL: 3-14.

[20] Huckin, T. and J. Coady. (1999). Incidental Vocabulary Acquisition in a Second Language: a Review. In Wesche and Paribakht, 1999: 181-93.

[21] Leek, P. and Shaw, P. (2000). Learners' Independent records of Vocabulary. System, 28/2: 271-289.

[22] O’Malley, J. M., Chamot, A. U., Gloria, S. M., Kupper, L. and
Russo, R. P.(1985). Learning strategies used by beginning and intermediate ESL students. Language Learning, 35: 21-46.

[23] Ellis, N. and Beaton, A. (1993). Psycholinguistics determinants of foreign language vocabulary learning. Language Learning, 43: 559-617.

[24] Ghazal, L. (2007). Learning Vocabulary in EFL Contexts Through Vocabulary Learning Strategies. [online]. Available: http://novitasroyal.org/Ghazal.pdf.

[25] Nation, I. S. P. (2004). Teaching and learning vocabulary. Beijing: Foreign Language Teaching and Research Press.

[26] Kojic-Sabo, I. and P. M. Lightbown. (1999). Students' approaches to vocabulary learning and their relationship to success. Modern Language Journal, 83: 176-192. 